\title{
Clinical characteristics and laboratory features of COVID-19 in high altitude areas: A retrospective cohort study
}

\author{
Hanxiao Chen $^{1}$, Lang Qin ${ }^{1}$, Sixian $\mathrm{Wu}^{1}$, Wenming $\mathrm{Xu}^{1}$, Rui $\mathrm{Gao}^{1}$, and Xiaohong Zhang ${ }^{2}$ \\ ${ }^{1}$ Sichuan University West China Second University Hospital \\ ${ }^{2}$ Sichuan Provincial People's Hospital
}

October 13, 2020

\begin{abstract}
Background: Coronavirus disease 2019 (COVID-19) is highly contagious and has affected the whole world. We aim to investigate the clinical and laboratory characteristics of COVID-19 patients in high altitude areas of Sichuan, China. Methods: In this retrospective cohort study, a total of 67 patients with laboratory-confirmed SARS-CoV-2 infection in Tibetan Qiang Autonomous Prefecture of Ngawa, Sichuan were included from February 1, 2020 to March 2, 2020. The clinical characteristics as well as their radiological and laboratory features were extracted. Results: $4(6.0 \%)$ patients were categorized into severe cases, $39(58.2 \%)$ were non-severe cases, and 24(35.8\%) were asymptomatic cases. $46(68.7 \%)$ patients were associated with cluster infection events in this study. The most common symptoms were cough, sputum production, dyspnea, fatigue or myalgia, and headache. $7(10.4 \%)$ patients showed leucopenia and $20(29.9 \%)$ patients showed lymphopenia. Lymphocyte count and neutrophil-to-lymphocyte ratio (NPR) was different between three groups. 14 (20.9\%) patients had thrombocytopenia, prothrombin time (PT) and fibrinogen levels differed between groups. We also found significant difference of sodium, chloride, and calcium levels between three groups. Antiviral therapy did not lead to obvious adverse event or shorter duration from initial positive to subsequent negative nuclei acid tests. Advanced age, hypertension, high neutrophil count, neutrophil-to-lymphocyte ratio, fibrinogen, and lactate dehydrogenase level were identified as independent risk factors for symptomatic cases of COVID-19. Conclusions: The symptoms of patients in high altitude areas were mild and about one third were asymptomatic. We also identified several independent risk factors for symptomatic cases of COVID-19.
\end{abstract}

\section{Hosted file}

20201010-manuscript.pdf available at https://authorea.com/users/366878/articles/486491clinical-characteristics-and-laboratory-features-of-covid-19-in-high-altitude-areas-aretrospective-cohort-study

\section{Hosted file}

Table 1.pdf available at https://authorea.com/users/366878/articles/486491-clinicalcharacteristics-and-laboratory-features-of-covid-19-in-high-altitude-areas-aretrospective-cohort-study

\section{Hosted file}

Table 2.pdf available at https://authorea.com/users/366878/articles/486491-clinicalcharacteristics-and-laboratory-features-of-covid-19-in-high-altitude-areas-aretrospective-cohort-study

\section{Hosted file}


Table 3.pdf available at https://authorea.com/users/366878/articles/486491-clinicalcharacteristics-and-laboratory-features-of-covid-19-in-high-altitude-areas-aretrospective-cohort-study

\section{Hosted file}

Table 4.pdf available at https://authorea.com/users/366878/articles/486491-clinicalcharacteristics-and-laboratory-features-of-covid-19-in-high-altitude-areas-aretrospective-cohort-study 